\title{
Exacerbation-related impairment of quality of life and work productivity in severe and very severe chronic obstructive pulmonary disease
}

This article was published in the following Dove Press journal:

International Journal of COPD

9 December 2013

Number of times this article has been viewed

\author{
Caitlyn T Solem' \\ Shawn X Sun ${ }^{2}$ \\ Lavanya Sudharshan' \\ Cynthia Macahilig 3 \\ Monica Katyal ${ }^{3}$ \\ Xin Gao'
}

'Pharmerit International, Bethesda, MD, USA; ${ }^{2}$ Forest Research Institute, Jersey City, NJ, USA; ${ }^{3}$ Medical Data Analytics, Parsippany, NJ, USA
Correspondence: Caitlyn T Solem Pharmerit US, 4350 East West Highway, Suite 430, Bethesda, MD 208I4, USA

$\mathrm{Tel}+\mathrm{I} 24082$ I 1267

Fax + I 24082 I 1296

Email csolem@pharmerit.com
Purpose: Exacerbation-associated health-related quality of life (HRQoL) in patients with severe and very severe chronic obstructive pulmonary disease (COPD) is ill-defined. This study describes patterns, HRQoL, and the work productivity impact of COPD-related moderate and SEV exacerbations in patients with SEV/VSEV COPD, focusing on the chronic bronchitis subtype.

Patients and methods: A US sample of SEV and VSEV COPD patients with recent moderate or SEV exacerbation was recruited. Along with the demographic and clinical data collected from medical records, patients reported on exacerbation frequency, health-related quality of life (HRQoL) (using the St George's Respiratory Questionnaire for COPD [SGRQ-C] and the European Quality of Life-5 Dimensions [EQ-5D] ${ }^{\mathrm{TM}}$ index), and work productivity and activity impairment (using the Work Productivity and Activity Impairment Questionnaire - Specific Health Problem [WPAI-SHP]). The HRQoL-related impacts of exacerbation frequency, time since exacerbation, and last exacerbation severity were evaluated via linear regressions.

Results: A total of 314 patients (190 SEV/124 VSEV, mean age $=68.0$ years, $51 \%$ male, $28 \%$ current smokers) were included. In the previous 12 months, patients reported an average of 1.8 moderate exacerbations and 0.9 SEV exacerbations. Overall, $16 \%$ of patients were employed and reported a high percentage of overall work impairment $(42.4 \% \pm 31.1 \%)$. Activity impairment was positively associated with recent exacerbation severity (SEV $64.6 \% \pm 26.8 \%$ versus moderate $55.6 \% \pm 28.2 \%)(P=0.006)$. The HRQoL was significantly worse for SEV versus VSEV COPD (EQ-5D: $0.62 \pm 0.23$ versus $0.70 \pm 0.17$, respectively, and SGRQ-C: $70.1 \pm 21.3$ versus $61.1 \pm 19.0$, respectively) $(P<0.001)$. Worse current HRQoL was reported by patients with a SEV versus moderate recent exacerbation (EQ-5D: $0.63 \pm 0.21$ versus $0.70 \pm 0.20$, respectively) $(P=0.003)$; SGRQ-C: $70.3 \pm 19.9$ versus $61.7 \pm 20.1$, respectively $(P<0.001)$. One additional exacerbation in the previous 12 months was associated with a 2.4-point SGRQ-C increase and a 0.02-point EQ-5D index decrease.

Conclusion: The severity and frequency of COPD-related moderate/SEV exacerbations in SEV and VSEV COPD patients were positively associated with poor HRQoL and work productivity and activity impairment.

Keywords: burden, HRQoL, chronic obstructive pulmonary disease, health-related quality of life, exacerbations, utilities

\section{Introduction}

Chronic obstructive pulmonary disease (COPD) is a slowly progressive condition affecting approximately 24 million adults in the United States, an estimated $50 \%$ of whom are undiagnosed. ${ }^{1}$ Affected patients suffer from frequent and recurrent exacerbations, which are defined by the Global Initiative for Chronic Obstructive Lung Disease (GOLD) as events in the course of COPD, characterized by acute changes in 
patients' baseline dyspnea, cough, and/or sputum exceeding ordinary day-to-day variations and which may warrant changes to medication. ${ }^{2}$ Accordingly, COPD exacerbations are associated with rapid decline in lung function and physical activity, increased risk of hospitalization and mortality, 3,4 deterioration in health-related quality of life (HRQoL), and substantial financial burden. , $^{3,5}$

Previous studies have noted the impact of increasing disease severity on HRQoL, ${ }^{7-10}$ that patients experiencing an exacerbation have worse HRQoL versus patients with stable disease, ${ }^{11}$ and that HRQoL deteriorates with frequent exacerbations. ${ }^{12}$ However, further evidence of the real-world impact of exacerbations on HRQoL and work impairment in actively-treated COPD patients is essential, particularly for high risk severe and very severe COPD patients. ${ }^{13}$ Of note, there have been no published analyses comparing the effects of varying levels of exacerbation severity among severe and very severe COPD patients.

To this end, the objective of this study was to describe COPD exacerbation burden in terms of exacerbation frequency and severity, HRQoL, and impact on work productivity, in patients with severe or very severe COPD, with a focus on the chronic bronchitis subtype, and to explore the relationship between exacerbation frequency/severity and patients' HRQoL and work productivity.

\section{Material and methods}

This study combined a retrospective observational chart review with a cross-sectional patient survey, to assess patients who had been diagnosed with severe or very severe COPD and who had experienced a moderate or severe exacerbation within 3 months prior to data collection. The medical charts of enrolled patients were reviewed to collect clinical/medicalrelated information, and then all patients were surveyed to collect matched data on HRQoL and work productivity. This study was conducted in compliance with the Health Insurance Portability and Accountability Act of $1996^{14}$ and was exempted from patient consent by New England Institutional Review Board.

\section{Study design}

Data collection (from recruitment of the first physician through completion of the last documents) occurred between November 23, 2011 and March 30, 2012.

\section{Physician selection}

A stratified random quota sample of 100 physicians (with a target of equal representation by pulmonologists and primary care physicians drawn in equal proportions from the four major census regions of the United States) were identified from a national database provided by F1rstMark, Inc. (Campton, NH, USA) and recruited via telephone. The physicians were screened to ensure that they were currently managing/treating severe and/or very severe COPD patients (as defined by GOLD guidelines) ${ }^{15}$ and that they were willing to comply with study instructions.

\section{Patient selection}

From among all adults ( $>40$ years old) who had been diagnosed with severe or very severe COPD for $\geq 12$ months prior to their most recent visit, had a chronic productive cough for $\geq 3$ months, and who experienced $\geq 1$ moderate or severe exacerbation (based on the American Thoracic Society/ European Respiratory Society-proposed categories for COPD exacerbation severity) ${ }^{16}$ within the previous 3 months, each included physician was asked to randomly select up to four adults from his/her practice, using patient birth month and day as the selection criteria, with a randomly chosen starting point for birth month/day that varied across sites.

\section{Data collection instruments}

A patient case report form was developed to abstract the clinical/medical information from the patient medical record, and a physician practice profile form was also completed by the physician to profile the treatment site/ clinical practice. Patient interview data were collected via a computer-assisted telephone interview technique. Alternatively, patients were also provided the option of completing a paper and pencil version of the instrument. The data elements collected from the physicians' practice profile forms, patients' medical charts, and patient surveys are summarized in Figure 1.

\section{Outcomes}

The key outcomes included the frequency of exacerbations in the previous 12 months, patient-reported HRQoL, and patient-reported work productivity and impairment.

\section{COPD severity}

Spirometry readings and COPD symptoms were collected at the initial COPD diagnosis, at the initial diagnosis of severe/ very severe COPD, and at the most recent visit. Patient severity was classified based on the physician report at the time of the diagnosis of severe/very severe COPD or at their most recent visit (maximum value observed). Physicians were provided with the following references for diagnosing 


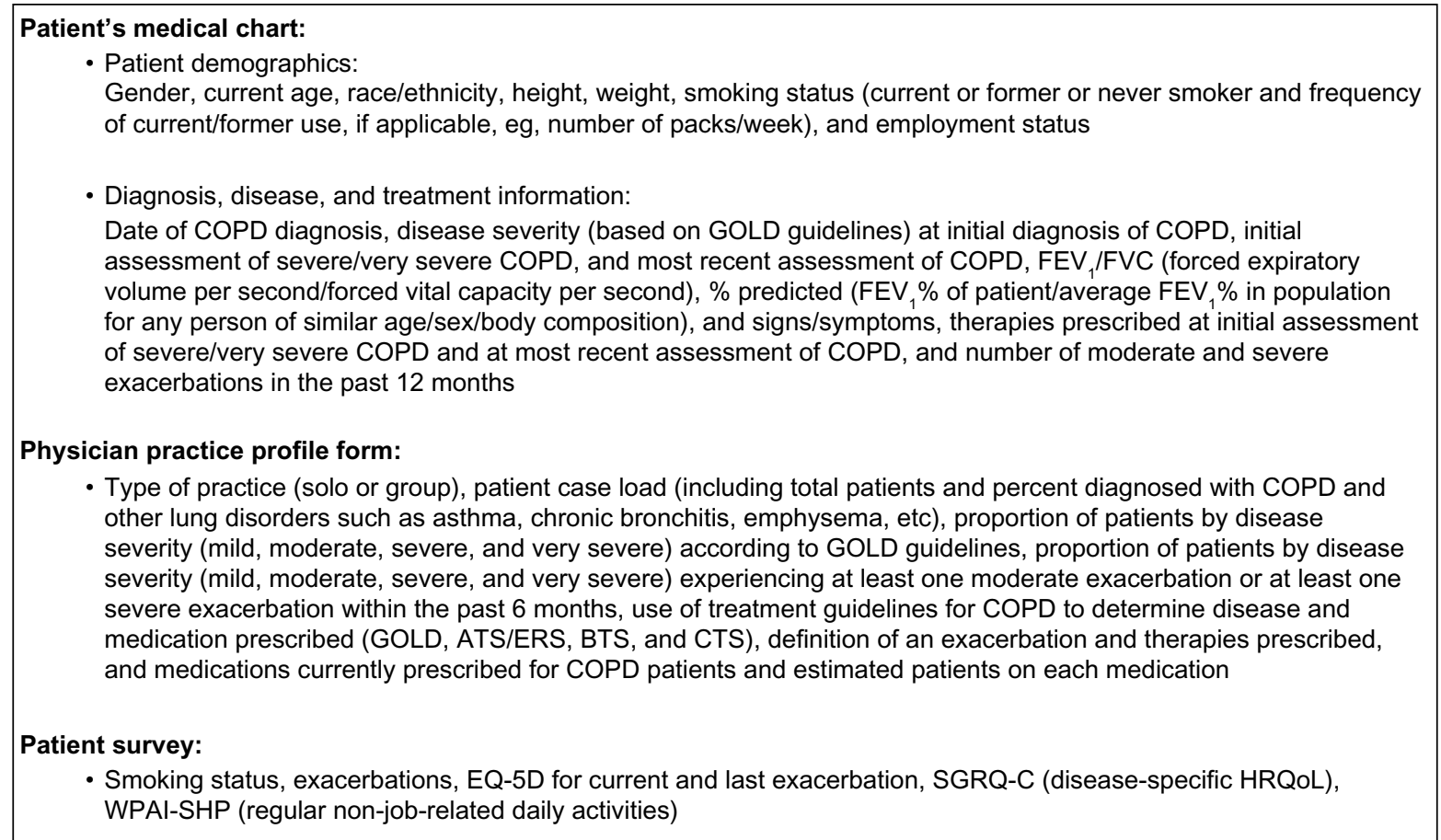

Figure I Data elements collected within the study.

Abbreviations: ATS, American Thoracic Society; BTS, British Thoracic Society; COPD, chronic obstructive pulmonary disease; CTS, Canadian Thoracic Society; ERS, European Respiratory Society; FEV , forced expiratory volume in I second; FVC, forced vital capacity; GOLD, Global Initiative for Chronic Obstructive Lung Disease; HRQoL, health-related quality of life; SGRQ-C, St George's Respiratory Questionnaire for COPD; WPAI-SHP, Work Productivity and Activity Impairment Questionnaire - Specific Health Problem.

COPD severity based on spirometry readings (consistent with GOLD guidelines): ${ }^{15}$ mild = forced expiratory volume in 1 second/forced vital capacity $\left(\mathrm{FEV}_{1} / \mathrm{FVC}\right)<0.7$ and $\mathrm{FEV}_{1} \geq 80 \%$ predicted; moderate $=\mathrm{FEV}_{1} / \mathrm{FVC}<0.7$ and $50 \% \leq \mathrm{FEV}_{1}<80 \%$ predicted; severe $=\mathrm{FEV}_{1} / \mathrm{FVC}<0.7$ and $30 \% \leq \mathrm{FEV}_{1}<50 \%$ predicted; and very severe $=\mathrm{FEV}_{1} /$ FVC $<0.7$ and $\mathrm{FEV}_{1}<30 \%$ predicted; however, they were not restricted to using only spirometry-based definitions (ie, they could base their severity rating on other factors beyond spirometry). Patients' worst severity was measured based on the maximum level of physician-reported severity attained at their most recent visit or at their initial diagnosis of severe/ very severe COPD.

\section{Exacerbations}

Exacerbation severity was classified as mild (increase in respiratory symptoms controllable by an increase of usual medication), moderate (requiring treatment with systemic steroids and/or antibiotics), or severe (requiring hospitalization or a visit to the emergency department), consistent with the American Thoracic Society/European Respiratory Society proposed categories for COPD exacerbation severity. ${ }^{16}$ The number of moderate and severe exacerbations occurring within the previous 12 months was collected from both patients' medical charts (primary source) and by direct patient report (secondary source). Patients also directly reported the number of mild exacerbations experienced in the previous 12 months. Chart data were used to classify a patient's most recent exacerbation as moderate or severe.

\section{Health-related quality of life}

HRQoL data were collected via patient interview, using both a generic (European Quality of Life-5 Dimensions ${ }^{17}$ [EQ$5 \mathrm{D}]^{\mathrm{TM}}$ ); and a disease-specific (St George's Respiratory Questionnaire for $\mathrm{COPD}^{20}$ [SGRQ-C]) instrument. The EQ-5D measures five single-item dimensions (Mobility, Self-Care, Usual Activities, Pain/Discomfort, and Anxiety/Depression), each with three levels of response (no, some, or extreme problems). ${ }^{17}$ The reliability, validity, and responsiveness of this measure in COPD has been previously established. ${ }^{18}$ Patients were asked to answer the EQ-5D items twice: once to rate their health on the day of the interview using the standard frame of reference for the EQ-5D and then, using a modified version of the EQ-5D that asked the patients to recall their health status during their last moderate or severe 
exacerbation. These responses were converted into utilities using the United States algorithm. ${ }^{19}$

The SGRQ-C is an adaptation of the SGRQ that was designed specifically to focus on COPD patients and their unique symptom profile. ${ }^{20}$ The SGRQ-C provides a total score and also, component scores for Symptoms, Activities, and Impacts, each of which ranges from 0 to 100, with directionality such that higher scores reflect worse HRQoL.

\section{Work productivity}

The Work Productivity and Activity Impairment Questionnaire - Specific Health Problem (WPAI-SHP) ${ }^{21}$ was used to measure work and activity impairment in COPD patients, with a 7-day recall period. The WPAI-SHP was previously used within a COPD population and found to have "good to acceptable" ease of completion in $83 \%$ of subjects. ${ }^{10}$

The WPAI-SHP consists of six items designed to measure work and activity impairment during the previous 7 days. The first question asks whether subjects are currently employed; if yes, questions 2 to 5 ask the subjects for the number of hours missed from work because of problems associated with the disease and the extent to which the problem affected their productivity while they were working (from "no effect on my work" to "completely prevented me from working") during the previous 7 days. In addition to measuring work productivity, the WPAI-SHP questionnaire (the last question) asks patients about the extent to which their condition limits them in the performance of regular non-job-related daily activities. The WPAI-SHP outcomes are expressed as impairment percentages, with higher numbers indicating greater impairment and less productivity.

\section{Statistical analyses}

Outcomes were described and compared across COPD severity levels (severe or very severe) and by the severity of patients' most recent exacerbation (moderate or severe), which by design occurred within 3 months of survey completion. Chi-squared tests were used for bivariate comparisons of the categorical variables (eg, exacerbation rates) and one-way analysis of variance (ANOVA) for continuous variables. All tests assumed a two-sided significance level of 0.05 .

Pearson correlations between the severity and frequency of exacerbations reported in the previous 12 months, HRQoL, and WPAI-SHP scores were calculated in order to explore the relationship between exacerbations and HRQoL. Furthermore, multiple linear regressions evaluated the impact of the total number of exacerbations in the previous year, the time since exacerbation, and the severity of the last exacerbation as per the SGRQ-C total scores and EQ-5D index, controlling for COPD severity, age, and race ethnicity.

\section{Results}

A total of 99 physicians (45 pulmonologists/54 primary care physicians) recruited 314 COPD patients for the study (190 severe/124 very severe). Among the recruited patients, $205(65.3 \%)$ and $109(34.7 \%)$ had recently experienced a moderate or a severe exacerbation, respectively, and 40 patients $(12.7 \%)$ were experiencing an exacerbation at the time that the survey was completed.

\section{Patient demographics}

The patients were predominantly white $(86.6 \%), 51.3 \%$ male, with mean \pm standard deviation age of $68.0 \pm 9.6$ years, and almost all patients were current $(27.7 \%)$ or former $(66.6 \%)$ smokers (Table 1). There were no significant differences in patient demographics, at the time of survey, between patients with severe versus very severe COPD or between patients with a moderate versus severe last exacerbation.

\section{COPD history, symptoms, and treatment}

The average duration from the time of COPD diagnosis to the time of patients' most recent physician visit was $6.4 \pm 5.2$ years $(5.9 \pm 4.9$ for severe COPD; $7.2 \pm 5.6$ for very severe COPD). At their most recent visit, patients had been diagnosed with severe or very severe COPD for $3.7 \pm 3.4$ years.

The most frequently observed symptoms for COPD patients at their most recent visit were shortness of breath upon exertion (84.7\%) and reduced exercise capacity (83.4\%) (Figure 2). Patients were treated with a mean of $3.8 \pm 1.2$ medications, with inhaled corticosteroids (83.8\%), short-acting beta agonists (83.1\%), long-acting beta agonists (81.8\%), and long-acting anticholinergics $(74.2 \%)$ being most frequently prescribed. In addition, $65.4 \%$ patients who had recently experienced a moderate exacerbation and $85.3 \%$ who had experienced a severe exacerbation were on oxygen therapy.

\section{Exacerbations}

Severe COPD patients were more likely to have their last exacerbation be moderate (70.5\% moderate versus $29.5 \%$ severe exacerbations), while very severe patients were more evenly divided between moderate and severe exacerbations (57.3\% versus $42.7 \%$ ). Based on the chart documentation, the patients had experienced an average of $2.6 \pm 0.16$ moderate 
Table I Patient characteristics

\begin{tabular}{|c|c|c|c|c|}
\hline & $\begin{array}{l}\text { Overall } \\
(N=3 \mid 4)\end{array}$ & $\begin{array}{l}\text { Severe COPD } \\
(\mathbf{N}=190)\end{array}$ & $\begin{array}{l}\text { Very severe COPD } \\
(\mathbf{N}=124)\end{array}$ & $P$-value \\
\hline Age, mean (SD) & $68.0(9.6)$ & $67.4(9.8)$ & $68.8(9.2)$ & 0.21 \\
\hline Male, n (\%) & $161(51.3)$ & $94(49.5)$ & $67(54.0)$ & 0.43 \\
\hline \multicolumn{5}{|l|}{ Body mass index, $\mathrm{n}(\%)$} \\
\hline Underweight $\left(<18.5 \mathrm{~kg} / \mathrm{m}^{2}\right)$ & $15(4.8)$ & $7(3.7)$ & $8(6.5)$ & \\
\hline Normal $\left(18.5-24.9 \mathrm{~kg} / \mathrm{m}^{2}\right)$ & $99(31.5)$ & $52(27.4)$ & 47 (37.9) & \\
\hline Overweight $\left(25.0-29.9 \mathrm{~kg} / \mathrm{m}^{2}\right)$ & $92(29.3)$ & $56(29.5)$ & $36(29.0)$ & \\
\hline Obese $\left(\geq 30.0 \mathrm{~kg} / \mathrm{m}^{2}\right)$ & $108(34.4)$ & 75 (39.5) & $33(26.6)$ & \\
\hline White, n (\%) & $272(86.6)$ & I56 (82.I) & $116(93.5)$ & 0.004 \\
\hline Ever smoked, n (\%) & $296(94.3)$ & $175(92.1)$ & $|2|(97.6)$ & 0.041 \\
\hline Current & $87(27.7)$ & 53 (27.9) & $34(27.4)$ & \\
\hline Former & $209(66.6)$ & $122(64.2)$ & $87(70.2)$ & \\
\hline Years since COPD diagnosis (any stage), mean (SD) & $6.4(5.2)$ & $5.9(4.9)$ & $7.2(5.6)$ & \\
\hline Years since severe/very severe COPD diagnosis, mean (SD) & $3.7(3.4)$ & $3.3(3.0)$ & $4.4(3.8)$ & \\
\hline $\mathrm{FEV}_{1} / \mathrm{FVC} \%$ at most recent visit, mean (SD) & $49(13.0)$ & $51.9(12.0)$ & $44.5(13.4)$ & $<0.001$ \\
\hline$\%$ predicted at most recent visit, mean (SD) & $45.2(13.9)$ & $48.7(12.0)$ & $40.1(14.8)$ & $<0.001$ \\
\hline \multicolumn{5}{|l|}{ Treatment regimens, $\mathrm{n}(\%)^{\mathrm{a}}$} \\
\hline SABA + LAMA + LABA + ICS & $82(26.4)$ & $45(24.1)$ & $37(29.8)$ & \\
\hline SAMA + SABA + LAMA + LABA + ICS & $32(10.3)$ & $13(7.0)$ & $19(15.3)$ & \\
\hline SABA + LAMA + LABA + ICS + PDE4I & $28(9.0)$ & $15(8.0)$ & $13(10.5)$ & \\
\hline LAMA + LABA + ICS & $18(5.8)$ & $10(5.3)$ & $8(6.5)$ & \\
\hline$S A B A+L A B A+I C S$ & $18(5.8)$ & $16(8.6)$ & $2(1.6)$ & \\
\hline SAMA + SABA + LAMA + LABA + ICS + PDE4I & $16(5.1)$ & $10(5.3)$ & $6(4.8)$ & \\
\hline Employment & & & & 0.09 \\
\hline Employed, full-time & $36(11)$ & $28(15)$ & $8(6.5)$ & \\
\hline Employed, part-time & $14(4.5)$ & $9(4.7)$ & $5(4)$ & \\
\hline Unemployed & $34(11)$ & $19(10)$ & $15(12)$ & \\
\hline Retired & $182(58)$ & III (58) & 7I (57) & \\
\hline Disabled & $48(15)$ & $23(12)$ & $25(20)$ & \\
\hline
\end{tabular}

Note: a Only displaying regimens used in $>5 \%$ patients.

Abbreviations: COPD, chronic obstructive pulmonary disease; FEV , forced expiratory volume in I second; FVC, forced vital capacity; ICS, inhaled corticosteroids; LABA, long-acting $\beta_{2}$-agonist; LAMA, long-acting muscarinic antagonist; PDE4I, phosphodiesterase-4 inhibitor; SABA, short-acting $\beta_{2}$-agonist; SAMA, short-acting muscarinic antagonist; SD, standard deviation.

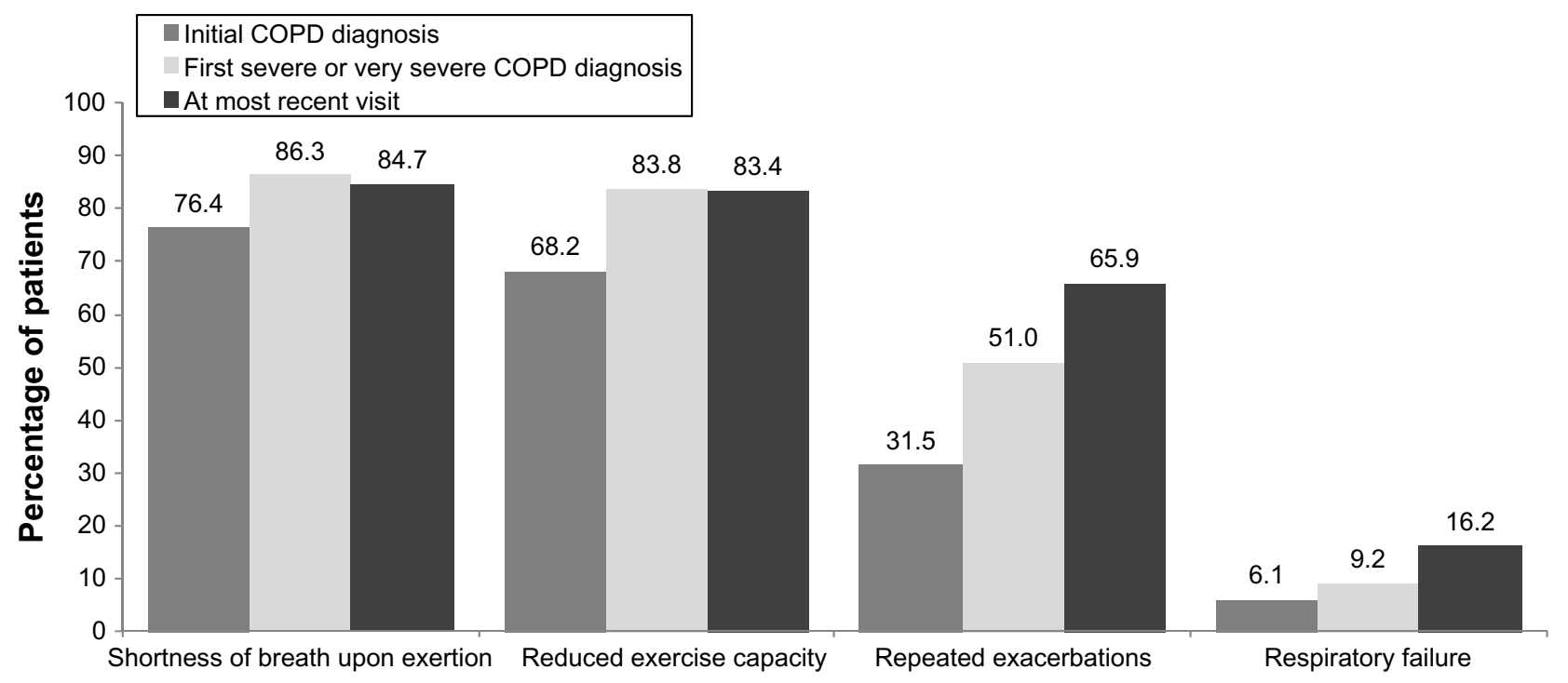

Figure 2 Patient symptoms at initial diagnosis, initial severe/very severe diagnosis, and most recent COPD visit.

Abbreviation: COPD, chronic obstructive pulmonary disease. 
(requiring systemic corticosteroid or antibiotic treatment) or severe (requiring an emergency room [ER] visit or hospitalization) exacerbations in the previous 12 months, with a total of 556 moderate exacerbations (mean length $10.7 \pm 8.4$ days) and 273 severe exacerbations (mean length $9.7 \pm 5.8$ days) recorded. Patients with very severe COPD had experienced significantly more severe exacerbations in the previous 12 months versus severe COPD patients (mean $1.1 \pm 0.19$ versus $0.7 \pm 0.14$ ) $(P<0.01)$. (Figure 3$)$. The majority of patients $(65 \%)$ also reported experiencing two or more mild exacerbations that may only have required an increase in the use of their maintenance medications, with a mean estimate of $7.2 \pm 25.8$ per year.

The majority $(63.4 \%)$ of moderate exacerbations were treated with both oral corticosteroids and antibiotics. Among the patients whose most recent exacerbation was severe, $17.4 \%$ were treated through an ER visit alone, $24.8 \%$ were treated on an inpatient basis, $49.5 \%$ started in the ER but resulted in a hospitalization, and nine patients ( $8.3 \%)$ had no hospitalization or ER visit, based on the physician report. The patients who had experienced $\geq 1$ additional exacerbation in the previous 12 months reported having a mean of 15 weeks since their previous exacerbation (Table 2).

\section{HRQoL}

The mean observed SGRQ-C Symptoms, Activities, and Impact scores were 70.6 $\pm 19.0,78.0 \pm 21.9$, and 54.7 \pm 24.8 , respectively, indicating a high level of impairment of quality of life due to COPD in these patients. Those whose most recent exacerbation was severe (versus moderate) had significantly higher Symptoms $(73.6 \pm 17.2$ versus $69.1 \pm 19.8)(P<0.05)$,
Activity $(83.6 \pm 18.3$ versus $75.1 \pm 23.0)(P=0.001)$, and Impact $(61.3 \pm 25.9$ versus $51.2 \pm 23.5)(P<0.001)$ scores (Table 3). Patients with very severe COPD also had higher Symptoms, Activities, and Impact scores compared with patients with severe COPD (all $P \leq 0.001$ ). Significant differences on the SGRQ-C Symptoms, Activities, and Impact scores were seen based on the time since last exacerbation ( $P<0.001$ for current versus $<1$ month, versus $1-2$ months, and versus $>2$ months post exacerbation ), with worse scores seen among patients currently experiencing exacerbation (total score: $69.8 \pm 17.0$; Symptoms score: $74.7 \pm 17.0$; and Impacts score: $60.4 \pm 21.3$ ). The SGRQ-C total scores were also significantly higher in patients whose recent exacerbation was severe versus moderate $(70.3 \pm 19.9$ versus $61.7 \pm 20.1)$ $(P<0.001)$, in patients with very severe versus severe COPD $(70.1 \pm 21.3$ versus $61.1 \pm 19.0)(P<0.001)$, and in patients experiencing an exacerbation at the time of study versus those who were $>2$ months post exacerbation $(69.8 \pm 17.0$ versus $54.6 \pm 20.6)(P<0.001)$. The SGRQ-C total scores were significantly worse for patients who had experienced three or more exacerbations $(69.5 \pm 18.7)$ compared with patients with one $(57.8 \pm 20)$ or two $(62.9 \pm 21.8)$ exacerbations in the previous year $(P<0.001)$. The SGRQ-C total scores were positively correlated with the number of patient-reported severe $(r=0.33, P<0.001)$, chart-recorded severe $(r=0.27$, $P<0.001)$, and total number of moderate and severe $(r=0.27$, $P<0.001)$ exacerbations in the previous year. When controlling for age, race/ethnicity, and COPD severity, the severity of the last exacerbation, the time since the last exacerbation, and the total number of moderate or severe exacerbations in

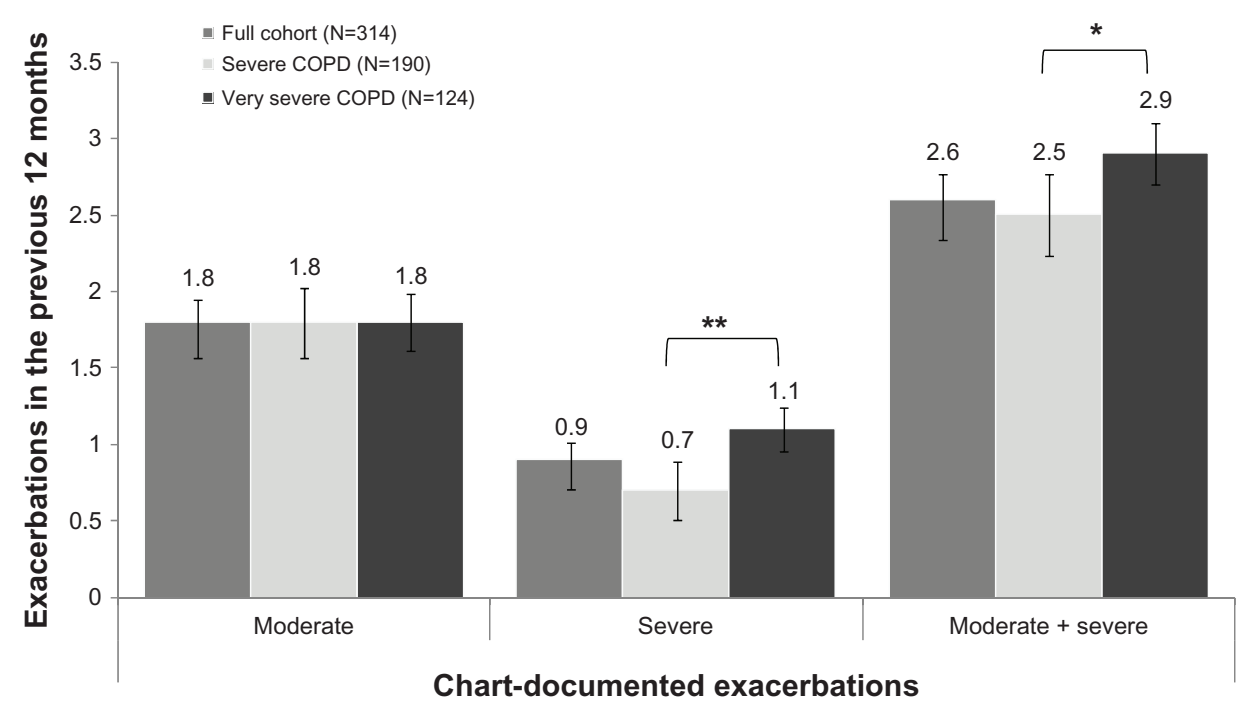

Figure 3 Mean exacerbations in the previous 12 months among COPD patients enrolled in the study.

Notes: $* P<0.05 ; * * P<0.01$.

Abbreviation: COPD, chronic obstructive pulmonary disease. 
Table 2 Exacerbation characteristics, by COPD severity and severity of last exacerbation

\begin{tabular}{|c|c|c|c|c|c|c|c|}
\hline & \multirow{2}{*}{$\begin{array}{l}\text { Overall } \\
(N=3 \mid 4)\end{array}$} & \multicolumn{3}{|c|}{ COPD severity } & \multicolumn{3}{|c|}{ Severity of last COPD exacerbation } \\
\hline & & $\begin{array}{l}\text { Severe } \\
(N=190)\end{array}$ & $\begin{array}{l}\text { Very severe } \\
(\mathrm{N}=124)\end{array}$ & $P$-value & $\begin{array}{l}\text { Moderate } \\
(\mathrm{N}=205)\end{array}$ & $\begin{array}{l}\text { Severe } \\
(N=109)\end{array}$ & $P$-value \\
\hline Exacerbation severity (from chart), n (\%) & & & & 0.005 & & & $<0.001$ \\
\hline Moderate & $202(64.3)$ & $134(70.5)$ & $68(54.8)$ & & |7| (83.4) & $31(28.4)$ & \\
\hline Severe & $112(35.7)$ & $56(29.5)$ & $56(45.2)$ & & $34(16.6)$ & $78(71.6)$ & \\
\hline $\begin{array}{l}\text { Treatment for moderate exacerbations } \\
\text { (from chart), } \mathrm{n}(\%)\end{array}$ & & & & 0.111 & & & \\
\hline Steroids and antibiotics & $130(63.4)$ & $83(61.9)$ & $47(66.2)$ & & $130(63.4)$ & - & \\
\hline Antibiotics only & $4 \mathrm{I}(20.0)$ & $32(23.9)$ & $9(12.7)$ & & $4 \mathrm{I}(20.0)$ & - & \\
\hline Steroids only & $34(16.6)$ & $19(14.2)$ & $15(21.1)$ & & $34(16.6)$ & - & \\
\hline $\begin{array}{l}\text { Location of severe exacerbation treatment } \\
\text { (from chart), } n(\%)\end{array}$ & & & & 0.289 & & & \\
\hline Hospitalized with ER visit & $54(49.5)$ & $23(4 I .1)$ & $31(58.5)$ & & - & $54(49.5)$ & \\
\hline ER visit, no hospitalization & $19(17.4)$ & $12(21.4)$ & $7(13.2)$ & & - & $19(17.4)$ & \\
\hline Hospitalized, no ER visit & $27(24.8)$ & $15(26.8)$ & $12(22.6)$ & & - & $27(24.8)$ & \\
\hline Recorded as severe - no ER or hospitalization & $9(8.3)$ & $6(10.7)$ & $3(5.7)$ & & - & $9(8.3)$ & \\
\hline Length of exacerbation (from chart), days & & & & 0.511 & & & 0.285 \\
\hline Mean (SD) & II.3 (8.9) & II.6 (9.9) & $10.9(7.2)$ & & II.7 (9.8) & $10.5(6.9)$ & \\
\hline Median (min, max) & $9.0(1,87)$ & $9.0(1,87)$ & $9.0(1,45)$ & & $9.0(1,87)$ & $9.0(I, 50)$ & \\
\hline Weeks since previous exacerbation (from chart) & & & & 0.254 & & & 0.025 \\
\hline Mean (SD) & $15.0(11.6)$ & $14.3(10.4)$ & $16.0(13.0)$ & & $16.3(11.6)$ & $12.7(\mid 1.4)$ & \\
\hline Median (min, max) & $11.3(0,47)$ & $11.6(1,45)$ & $10.8(0,47)$ & & $12.4(I, 47)$ & $8.4(0,45)$ & \\
\hline
\end{tabular}

Notes: abased on physician-reported estimate of severity at the most current visit or at the diagnosis of severe/very severe COPD. When there were discrepancies between the two time periods, the maximum severity level was used (eg, a patient who was diagnosed as severe but who was very severe at the most recent visit would be classified as very severe); 'blast exacerbation severity was based on information provided in the patient's medical chart. Moderate exacerbations were defined as those that could be treated using oral corticosteroids or antibiotics; severe exacerbations were those that involved a visit to an emergency department or a hospitalization; 'denominator is moderate exacerbations; ${ }^{d}$ denominator is severe exacerbations.

Abbreviations: COPD, chronic obstructive pulmonary disease; ER, emergency room; SD, standard deviation; min, minimum; max, maximum.

the previous 12 months were all significant predictors of the SGRQ-C total scores (Table 4).

With a trend similar to the SGRQ-C scores, the EQ-5D indices for current health illustrated significantly worse health for patients recently experiencing a severe versus moderate exacerbation $(0.627 \pm 0.210$ versus $0.698 \pm 0.197$, respectively) $(P<0.01)$, for patients who had very severe versus severe COPD $(0.623 \pm 0.234$ versus $0.707 \pm 0.174$, respectively) $(P<0.001)$, and for patients who had experienced three or more exacerbations in the previous year $(0.638 \pm 0.212)$ versus two exacerbations $(0.684 \pm 0.204)$ versus one exacerbation $(0.727 \pm 0.175)(P<0.01)$ (Table 3$)$. The EQ-5D indices for current HRQoL were most robustly correlated with the total number of chart-recorded moderate and severe exacerbations $(r=-0.21, P<0.001)$ and patientreported severe exacerbations $(r=-0.34, P<0.001)$ in the previous 12 months.

When patients thought back to their last exacerbation, their EQ-5D scores averaged $0.552( \pm 0.283)$, with greater disutility in patients with very severe COPD versus severe COPD $(0.494 \pm 0.312$ versus $0.590 \pm 0.256$, respectively $)$ $(P<0.01)$, for patients whose last exacerbation (for which they were providing the utility estimate) was severe versus moderate $(0.471 \pm 0.313$ versus $0.595 \pm 0.257$, respectively) $(P<0.001)$, and for patients who had experienced a higher frequency of exacerbations the previous year (three or more exacerbations: $0.520 \pm 0.282$, two exacerbations: $0.552 \pm 0.306$, one exacerbation: $0.610 \pm 0.254$ ). Of note, estimates for utilities during previous exacerbation were consistent with those provided for current health among the patients who were currently experiencing exacerbation $(0.599 \pm 0.220)$. When controlling for age, race/ethnicity, and COPD severity, the EQ-5D indices increased with time since exacerbation, decreased for each additional moderate/ severe exacerbation in the previous year, and were higher for severe versus very severe COPD (Table 4).

\section{Employment and work productivity}

Overall, 50 (15.9\%) respondents were employed at the time of survey, and employment status differed significantly by COPD severity (very severe COPD: 13 [10.5\%] versus severe COPD: $37[19.5 \%])(P<0.033)$ but not by the severity of the most recent exacerbation. Among the employed respondents, an average of $9.0 \% \pm 19.1 \%$ of work time was missed due to COPD, and patients estimated $38.8 \% \pm 28.2 \%$ impairment while at work, for an estimated $42.4 \% \pm 31.1 \%$ overall work impairment. 


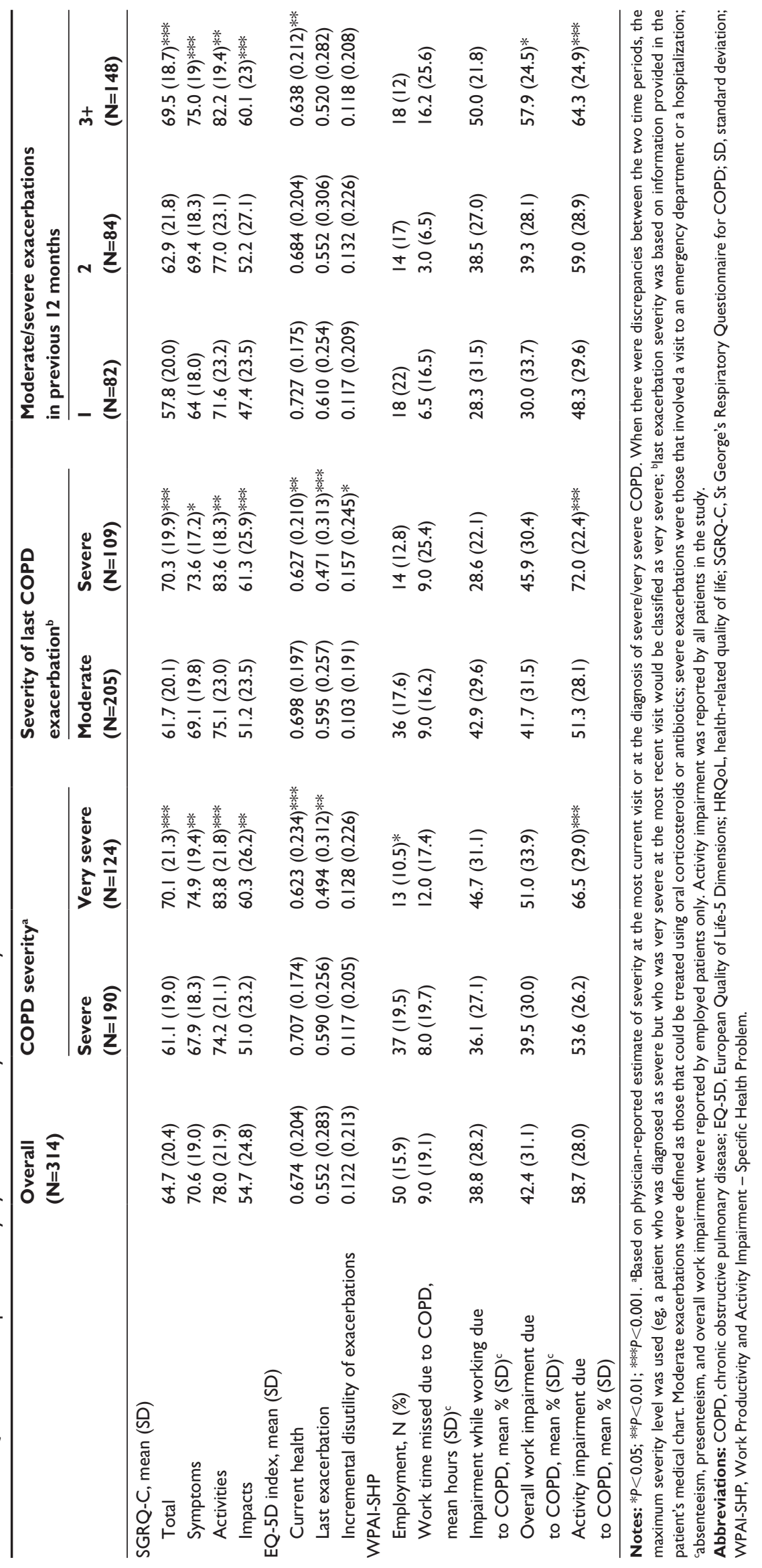


Table 4 Predictors of SGRQ-C total scores and EQ-5D index

\begin{tabular}{|c|c|c|c|c|c|c|}
\hline & \multicolumn{3}{|l|}{ SGRQ-C } & \multicolumn{3}{|l|}{ EQ-5D } \\
\hline & Estimate (SE) & $t$-value & $P$-value & Estimate (SE) & $t$-value & $P$-value \\
\hline Intercept & $76.08(8.69)$ & 8.76 & $<0.0001$ & $0.459(0.090)$ & 5.08 & $<0.0001$ \\
\hline \multicolumn{7}{|c|}{ Time since exacerbation (ref: current exacerbation) } \\
\hline$<\mathrm{I}$ month & $-1.58(3.65)$ & -0.43 & 0.6655 & $0.040(0.038)$ & 1.05 & 0.2933 \\
\hline I-2 months & $-0.92(3.28)$ & -0.28 & 0.7787 & $0.060(0.034)$ & 1.76 & 0.0794 \\
\hline$>2$ months & $-12.08(3.68)$ & -3.28 & 0.0012 & $0.110(0.038)$ & 2.86 & 0.0046 \\
\hline Last exacerbation moderate (ref: severe) & $-12.23(2.21)$ & -5.54 & $<0.0001$ & $0.109(0.023)$ & 4.73 & $<0.000$ I \\
\hline Number of moderate/severe exacerbations & $2.45(0.74)$ & 3.3 & 0.0011 & $-0.019(0.008)$ & -2.47 & 0.0140 \\
\hline \multicolumn{7}{|l|}{ in the previous 12 months (from chart) } \\
\hline Severe COPD (ref: very severe COPD) & $-5.07(2.18)$ & -2.33 & 0.0204 & $0.056(0.023)$ & 2.47 & 0.0141 \\
\hline Age & $-0.07(0.11)$ & -0.62 & 0.5368 & $0.001(0.001)$ & 1.12 & 0.2635 \\
\hline Nonwhite (ref: white) & $1.24(3.08)$ & 0.4 & 0.6876 & $0.018(0.032)$ & 0.56 & 0.5751 \\
\hline
\end{tabular}

Abbreviations: COPD, chronic obstructive pulmonary disease; EQ-5D, European Quality of Life-5 Dimensions; SE, standard error; SGRQ-C, St George's Respiratory Questionnaire for COPD.

Among all respondents, those who had recently experienced a severe exacerbation versus a moderate exacerbation had significantly more activity impairment $(72.0 \% \pm 22.4 \%$ versus $51.3 \% \pm 28.1 \%)(P<0.001)$, as did patients whose COPD was very severe versus severe $(66.5 \% \pm 29.0 \%$ versus $53.6 \% \pm$ $26.2 \%)(P<0.001)$. Significant activity impairment was also seen among patients with higher documented exacerbations in the previous year (three or more exacerbations: $64.3 \pm 24.9$, two exacerbations: $59.0 \pm 28.9$, and one exacerbation: $48.3 \pm 29.6$ ) $(P<0.001)$. Work impairment was worse among patients experiencing an exacerbation at the time of survey $(75.3 \% \pm 8.9 \%)$, with scores improving over time $(P=0.010)$.

The WPAI-SHP productivity loss was strongly correlated with the total number of chart-reported moderate exacerbations in the previous year $(r=0.52, P<0.001)$. Similarly, the total number of chart-documented severe exacerbations in the previous year was positively correlated with the activity impairment domain of the WPAI-SHP $(r=0.21, P<0.001)$. When assessing the association of work productivity to QoL, the EQ-5D indices for current health were strongly correlated with activity impairment $(r=-0.54, P<0.001)$ and productivity loss $(r=-0.50, P<0.001)$. The SQRQ-C total score had a moderate to strong correlation with almost all domains of the WPAI-SHP (presenteeism $[r=0.48, P<0.001]$; activity impairment $[r=0.70, P<0.0001]$; and productivity loss $[r=0.47, P<0.0001])$.

\section{Discussion}

The results of this study indicate that exacerbations significantly impact HRQoL and work productivity in severe and very severe COPD patients with chronic productive cough. Patients with severe and very severe COPD who recently experienced an exacerbation continued to experience diminished HRQoL, illustrating a lasting impact beyond the time of exacerbation. The findings from this study add to the growing evidence defining the exacerbation-associated burden in severe and very severe COPD patients.

The mean of 2.6 exacerbations per patient per year that was observed in this study was higher than that documented in previous studies. ${ }^{5,9}$ Thus, this study population allowed us to examine the burden of exacerbations in this highly severe population.

Overall, the mean SGRQ-C total scores found in this study were higher than those previously reported by Jones et al, ${ }^{11}$ based on a European cross-sectional study of patients being treated in primary care settings, stratified by disease severity. While Jones et $\mathrm{al}^{11}$ reported mean scores of $50.2 \pm 18.6$ versus $58.6 \pm 17.7$ for severe versus very severe COPD, respectively, the patients in the present study had mean scores over 10 points higher $(61.1 \pm 19.0$ versus $70.1 \pm 21.3$ for severe versus very severe, respectively). However, there were differences in the study population as compared to that of the current study, particularly that few participants in Jones et $\mathrm{al}^{11}$ had recently experienced an exacerbation, while all patients in the current population were either currently exacerbating or had recently had an exacerbation. The EQ-5D indices from the present study for severe $(0.707 \pm 0.174)$ and very severe $(0.623 \pm 0.234)$ COPD patients were quite similar to those previously reported in a review of the use of the EQ-5D in COPD. ${ }^{18}$ The utility estimates derived in the present study for severe exacerbations were lower than those observed by Menn et al, ${ }^{22}$ who examined health state utilities in severe COPD patients hospitalized for exacerbations and found a EQ-5D utility of 0.62 at admission and of 0.84 at discharge. This could also be due to differences in the underlying COPD severity of the patients studied, as it was also found that 
very severe patients reported lower utilities during their last exacerbation as compared with severe COPD patients.

Beyond statistical significance, differences in HRQoL scores can also be compared in terms of clinical significance. For example, one study reported a mean minimally important difference (MID) of 0.074 for the EQ-5D, based on data from eleven longitudinal studies. ${ }^{23}$ Using this difference, there was a clinically important difference between the EQ-5D scores reported for patients' current health as compared with their health during their last exacerbation; between the current and last exacerbation scores, by COPD severity; between the patients who had experienced one, two, or three or greater exacerbations in the previous year; and in the EQ-5D index for last exacerbation by whether that exacerbation was moderate or severe. For the SGRQ-C, the MID is 4 units. ${ }^{24,25}$ Using this value, there were clinically significant differences between the severe and very severe patients, between patients whose last exacerbation was moderate versus severe, and between the patients who had experienced one versus two versus three or more exacerbations in the previous year, for all SGRQ-C summary scores.

There is mixed evidence in the literature regarding the relationship between exacerbations and HRQoL. In a study conducted by Seemungal et $\mathrm{al}^{9}$ examining the effect of exacerbations on $\mathrm{HRQ}$ OL in patients with $\mathrm{FEV}_{1}<70 \%$ predicted, the SGRQ total and component scores were significantly worse in patients who had frequent exacerbations, and frequent exacerbations in the previous year were a predisposing factor to future frequent exacerbations (odds ratio $=5.5$ for the frequent versus infrequent group, $P=0.001$ ). In contrast, in a 2-year follow-up study conducted by Miravitlles et al, ${ }^{5}$ exacerbations had no effect on HRQoL in severe COPD patients, but significant impairment in HRQoL of patients with moderate COPD was observed. The present findings suggest a relationship between exacerbation frequency and the SGRQ-C score, with a 2.4-unit increase in scores for each additional moderate/severe exacerbation, but this could be partially attributable to the proximity between the patients' most recent exacerbation and the SGRQ-C measurement.

In addition to the HRQoL burden of COPD, work productivity and the ability to perform usual activities also suffer, particularly among severe and very severe COPD patients who have recently experienced an exacerbation. The impact of COPD on work productivity was consistent with a recent analysis of the 2009 National Health and Wellness Survey, which found that employed adults with COPD reported significantly lower work productivity (34.04\% overall work impairment). ${ }^{26}$
Several limitations of this study should be noted. The results will be most generalizable to similar patient populations, that is, patients with severe or very severe COPD within the US population, who have recently experienced a moderate to severe exacerbation. Even though random selection criteria were utilized, study designs such as ours are predisposed to selection bias. For example, the physicians in this study included those patients who could be contacted and were willing to participate, and they may have differed from those patients who did not wish to participate. Also, the participating physicians did not have the same number of patients, and some of the results may possibly be over- or underrepresented by patients from a particular practice.

Given that patients were recruited through their physicians, our patient population would exclude patients who otherwise would have met inclusion criteria, but who were not being actively treated. The patients who participated in this study were those who were still living, were not lost to follow-up, were successfully contacted, and who agreed to participate in the interview. The health status and profile of these patients may therefore differ from the US COPD population otherwise meeting the inclusion criteria. It should be noted that the utilities that were provided for the HRQoL during the patients' last exacerbation were gathered using a modified time frame for the EQ-5D (eg, recalling back to the last exacerbation) and may have been subject to recall bias and as such, should be interpreted with caution. However, the time since last exacerbation did not appear to influence patients' EQ-5D index score for their last exacerbation, which provides some confidence that the time elapsed between the exacerbation and the patient's response was not a significant predictor of the patients' EQ-5D index value for their last exacerbation. This would suggest that the recall bias with patient-reported outcomes was limited in our study, since the patient-reported outcomes were robust to time since exacerbation.

Despite these limitations, this study adds to the literature regarding the treatment of exacerbations and exacerbationrelated HRQoL measured in severe to very severe COPD patients, for which there is limited previous information. A sampling methodology was used to select a sample of patients with severe and very severe COPD patients from all regions of the United States and who were treated by both pulmonologists and primary care physicians. By combining chart-reported information about exacerbations and their treatment, which may be more precise and allows for the capture of more precise data on clinical severity, with patient 
reported outcomes, a more complete picture of the patients' experience is provided. These results can help to quantify the burden associated with severe and very severe COPD and provide inputs (in terms of utilities) for future economic models of treatments aimed to reduce exacerbation frequency in these types of COPD patients.

\section{Conclusion}

In conclusion, the burden of severe and very severe COPD patients is particularly high in patients who have recently experienced an exacerbation. These patients were also very likely to have experienced at least one additional moderate to severe exacerbation in the previous year, which contributes to poor HRQoL and impairs patients' ability to be productive and undertake normal activities. Avoiding exacerbations not only avoids the HRQoL decrement attributable to the first exacerbation, but may also reduce HRQoL impact on subsequent exacerbations. Interventions aiming to further reduce exacerbation occurrences will likely have a strong impact on COPD patients' HRQoL.

\section{Acknowledgment}

This study was funded by Forest Research Institute.

\section{Disclosure}

Assistance with the editing and formatting of the manuscript for submission by Prescott Medical Communications Group (Chicago, IL, USA) was made possible by funding from Forest Research Institute (Jersey City, NJ, USA), a wholly owned subsidiary of Forest Laboratories, Inc. (New York, NY, USA).

Caitlyn T Solem, Lavanya Sudharshan, and Xin Gao are employees of Pharmerit International and were paid consultants to Forest Research Institute in the development and execution of this study and manuscript. Cynthia Macahilig and Monica Katyal are employees of Medical Data Analytics and were paid consultants to Forest Research Institute for conducting the survey and for data collection. Shawn X Sun is an employee of Forest Research Institute, the sponsor of this study. The authors report no other conflicts of interest in this work.

\section{References}

1. Mannino DM, Buist AS. Global burden of COPD: risk factors, prevalence, and future trends. Lancet. 2007;370(9589):765-773.

2. Vestbo J, Hurd SS, Agustí AG, et al. Global strategy for the diagnosis, management, and prevention of chronic obstructive pulmonary disease: GOLD executive summary. Am J Respir Crit Care Med. 2013;187(4): 347-365.

3. Anzueto A, Leimer I, Kesten S. Impact of frequency of COPD exacerbations on pulmonary function, health status and clinical outcomes. Int J Chron Obstruct Pulmon Dis. 2009;4:245-251.
4. Gillissen A, Glaab T, Lewis M, Buhl R, Worth H. Statistical analysis of chronic obstructive pulmonary disease exacerbations in clinical studies: expectations and limitations. J Physiol Pharmacol. 2009; 60 Suppl 5:S7-S11.

5. Miravitlles M, Ferrer M, Pont A, et al; IMPAC Study Group. Effect of exacerbations on quality of life in patients with chronic obstructive pulmonary disease: a 2 year follow up study. Thorax. 2004;59(5): 387-395.

6. Toy EL, Gallagher KF, Stanley EL, Swensen AR, Duh MS. The economic impact of exacerbations of chronic obstructive pulmonary disease and exacerbation definition: a review. COPD. 2010;7(3): 214-228.

7. Llor C, Molina J, Naberan K, Cots JM, Ros F, Miravitlles M; EVOCA study group. Exacerbations worsen the quality of life of chronic obstructive pulmonary disease patients in primary healthcare. Int J Clin Pract. 2008;62(4):585-592.

8. Rutten-van Mölken MP, Oostenbrink JB, Tashkin DP, Burkhart D, Monz BU. Does quality of life of COPD patients as measured by the generic EuroQol five-dimension questionnaire differentiate between COPD severity stages? Chest. 2006;130(4):1117-1128.

9. Seemungal TA, Donaldson GC, Paul EA, Bestall JC, Jeffries DJ, Wedzicha JA. Effect of exacerbation on quality of life in patients with chronic obstructive pulmonary disease. Am J Respir Crit Care Med. 1998;157(5 Pt 1):1418-1422.

10. Ståhl E, Lindberg A, Jansson SA, et al. Health-related quality of life is related to COPD disease severity. Health Qual Life Outcomes. 2005;3:56

11. Jones PW, Brusselle G, Dal Negro RW, et al. Patient-centred assessment of COPD in primary care: experience from a cross-sectional study of health-related quality of life in Europe. Prim Care Respir J. 2012; 21(3):329-336.

12. Niewoehner DE. The impact of severe exacerbations on quality of life and the clinical course of chronic obstructive pulmonary disease. $\mathrm{Am}$ J Med. 2006;119(10 Suppl 1):S38-S45.

13. Hurst JR, Vestbo J, Anzueto A, et al. Susceptibility to exacerbation in chronic obstructive pulmonary disease. New Engl J Med. 2010; 363(12):1128-1138.

14. Health Information Privacy [webpage on the Internet]. Washington, DC: US Department of Health \& Human Services. Available from: http:// www.hhs.gov/ocr/privacy/hipaa/understanding/index.html. Accessed October 10, 2013.

15. Rabe KF, Hurd S, Anzueto A, et al; Global Initiative for Chronic Obstructive Lung Disease. Global strategy for the diagnosis, management, and prevention of chronic obstructive pulmonary disease: GOLD executive summary. Am J Respir Crit Care Med. 2007;176(6):532-555.

16. Celli BR, MacNee W; ATS/ERS Task Force. Standards for the diagnosis and treatment of patients with COPD: a summary of the ATS/ERS position paper. Eur Respir J. 2004;23(6):932-946.

17. Brooks R. EuroQol: the current state of play. Health Policy. 1996;37(1): 53-72.

18. Pickard AS, Wilke C, Jung E, Patel S, Stavem K, Lee TA. Use of a preference-based measure of health (EQ-5D) in COPD and asthma. Respir Med. 2008;102(4):519-536.

19. Szende A, Leidy NK, Ståhl E, Svensson K. Estimating health utilities in patients with asthma and COPD: evidence on the performance of EQ-5D and SF-6D. Qual Life Res. 2009;18(2):267-272.

20. Meguro M, Barley EA, Spencer S, Jones PW. Development and validation of an improved, COPD-specific version of the St George Respiratory Questionnaire. Chest. 2007;132(2):456-463.

21. Reilly MC, Zbrozek AS, Dukes EM. The validity and reproducibility of a work productivity and activity impairment instrument. Pharmacoeconomics. 1993;4(5):353-365.

22. Menn P, Weber N, Holle R. Health-related quality of life in patients with severe COPD hospitalized for exacerbations - comparing EQ-5D, SF-12 and SGRQ. Health Qual Life Outcomes. 2010;8:39.

23. Walters SJ, Brazier JE. Comparison of the minimally important difference for two health state utility measures: EQ-5D and SF-6D. Qual Life Res. 2005;14(6):1523-1532. 
24. Jones PW. Interpreting thresholds for a clinically significant change in health status in asthma and COPD. Eur Respir J. 2002;19(3): 398-404.

25. Jones PW. St George's Respiratory Questionnaire: MCID. COPD. 2005;2(1):75-79.
26. DiBonaventura Md, Paulose-Ram R, Su J, et al. The impact of COPD on quality of life, productivity loss, and resource use among the elderly United States workforce. COPD. 2012;9(1):46-57.

\section{Publish your work in this journal}

The International Journal of COPD is an international, peer-reviewed journal of therapeutics and pharmacology focusing on concise rapid reporting of clinical studies and reviews in COPD. Special focus is given to the pathophysiological processes underlying the disease, intervention programs, patient focused education, and self management protocols.
This journal is indexed on PubMed Central, MedLine and CAS. The manuscript management system is completely online and includes a very quick and fair peer-review system, which is all easy to use. Visit http://www.dovepress.com/testimonials.php to read real quotes from published authors.

Submit your manuscript here: http://www.dovepress.com/international-journal-of-copd-journal 